10

\title{
Фотолюминесценция и особенности дефектной структуры конгруэнтных и близких к стехиометрическому составу кристаллов ниобата лития, полученных по разным технологиям
}

\author{
(C) Н.В. Сидоров, М.В. Смирнов, Н.А. Теплякова , М.Н. Палатников \\ Институт химии и технологии редких элементов и минерального сырья им. И.В. Тананаева \\ Федерального исследовательского центра „Кольский научный центр Российской академии наук“, \\ 184209 Апатиты, Мурманская обл., Россия \\ 『e-mail: tepl_na@chemy.kolasc.net.ru \\ Поступила в редакцию 04.12.2019 г. \\ В окончательной редакции 05.12.2019 г. \\ Принята к публикации 06.02.2020 г.
}

\begin{abstract}
Исследована фотолюминесценция в объеме конгруэнтного и близких к стехиометрическому составу кристаллов ниобата лития, полученных по разным технологиям. Установлено, что интенсивность люминесценции в кристаллах, состав которых близок к стехиометрическому, ниже, чем в конгруэнтном кристалле. Показано, что вклад в люминесценцию могут вносить не только основные типы центров свечения, обусловленные наличием точечных дефектов $\mathrm{Nb}_{\mathrm{Li}}, V_{\mathrm{Li}}$ и других, но и комплексные дефекты, обусловленные присутствием в структуре ОН-групп.
\end{abstract}

Ключевые слова: стехиометрический и конгруэнтный кристаллы ниобата лития, фотолюминесценция, центры свечения, дефекты, ИК спектроскопия, оптическая спектроскопия.

DOI: $10.21883 /$ OS.2020.05.49324.333-19

\section{Введение}

Нелинейно-оптический монокристалл ниобата лития $\left(\mathrm{LiNbO}_{3}\right)$ обладает рядом уникальных физических характеристик и является одним из наиболее важных функциональных материалов электронной техники [1-3], технологии которого непрерывно совершенствуются [4-6]. Разнообразие дефектов (точечных и комплексных) в структуре сегнетоэлектрического кристалла $\mathrm{LiNbO}_{3}$, обладающего к тому же эффектом фоторефракции, приводит к появлению множества локализованных уровней энергий в запрещенной зоне, расположение которых зависит от величины $R$. Ширина запрещенной зоны для номинально чистого конгруэнтного кристалла $\mathrm{LiNbO}_{3}$ составляет $3.72 \mathrm{eV}$. Для стехиометрического $3.38 \mathrm{eV}$ [7], что близко к значению для широкозонных полупроводников. Переход возбужденного электрона между уровнями энергии в запрещенной зоне может приводить как к передаче энергии фононам решетки, так и к появлению излучения с определенной длиной волны. Особенности таких переходов определяют люминесцентные характеристики оптических материалов на основе кристалла $\mathrm{LiNbO}_{3}$.

Информация о люминесцентных свойствах кристаллов $\mathrm{LiNbO}_{3}$, состав которых близок к стехиометрическому составу, т. е. $R \sim 1$, представляет особый интерес. Близкие к стехиометрическому составу монокристаллы $\mathrm{LiNbO}_{3}$ обладают существенно меньшей величиной напряженности коэрцитивного поля $(\sim 3 \mathrm{kV} / \mathrm{mm})$ по сравнению с конгруэнтными кристаллами $(\sim 22 \mathrm{kV} / \mathrm{mm})$, что делает их привлекательными для разработки материалов для преобразования лазерного излучения на периодически поляризованных доменах субмикронных размеров [8]. Фотолюминесценция - серьезный лимитирующий фактор при преобразовании лазерного излучения нелинейно-оптическим кристаллом $\mathrm{LiNbO}_{3}$.

В данной работе представлены результаты сравнительных исследований фотолюминесценции в номинально чистом конгруэнтном кристалле $\left(\mathrm{LiNbO}_{3 \text { cong }}\right)$, а также в кристаллах, состав которых близок к стехиометрическому, полученных по двум технологиям: из расплава c $58.6 \mathrm{~mol}_{\%} \mathrm{Li}_{2} \mathrm{O}\left(\mathrm{LiNbO}_{3 \text { stoich }}\right)$ и по технологии HTTSSG (High temperature top speed solution growth [1,9-11]) из конгруэнтного расплава с добавлением флюса $6.0 \mathrm{wt} \%$ $\mathrm{K}_{2} \mathrm{O}\left(\mathrm{LiNbO}_{3 \text { stoich }}\left(6.0 \mathrm{wt} \% \mathrm{~K}_{2} \mathrm{O}\right)\right)$. Кристаллы $\mathrm{LiNbO}_{3 \text { stoich }}$ отличаются неоднородным показателем преломления вдоль оси роста $[2,6]$, что делает их непригодными для изготовления оптических элементов для преобразования лазерного излучения. По этой причине кристаллы $\mathrm{LiNbO}_{3 \text { stoich }}$ в промышленности в настоящее время не используются. Важное промышленное применение для разработки преобразователей лазерного излучения на периодически поляризованных доменах субмикронных размеров [8] могут найти кристаллы $\mathrm{LiNbO}_{3 \text { stoich }}$ $\left(6.0 \mathrm{wt} \% \mathrm{~K}_{2} \mathrm{O}\right)$, отличающиеся низким коэрцитивным полем и высокой однородностью показателя преломления вдоль оси роста, близкой к таковой для номинально чистого конгруэнтного кристалла. Этот факт обусловливает актуальность проведения сравнительных исследований люминесцентных и других свойств кристаллов $\mathrm{LiNbO}_{3}$, состав которых близок к стехиометрическому, полученных по разным технологиям. Ранее такие иссле- 
Таблица 1. Примесный состав исследованных кристаллов ниобата лития

\begin{tabular}{c|c|c}
\hline Примесь & $\begin{array}{c}\text { Концентрация } \\
\text { примеси в шихте, wt \% }\end{array}$ & $\begin{array}{c}\text { Содержание примеси } \\
\text { в кристалле, wt \% }\end{array}$ \\
\hline $\mathrm{Mn}, \mathrm{V}, \mathrm{Mg}$, & $<1 \cdot 10^{-4}$ & $<5 \cdot 10^{-4}$ \\
$\mathrm{Sn}, \mathrm{Cu}$ & & $<1 \cdot 10^{-3}$ \\
$\mathrm{~Pb}, \mathrm{Ni}, \mathrm{Cr}$ & $<1 \cdot 10^{-4}$ & $<1 \cdot 10^{-3}$ \\
$\mathrm{Co}, \mathrm{Mo}$ & $<4 \cdot 10^{-4}$ & $<1 \cdot 10^{-3}$ \\
$\mathrm{Si}, \mathrm{Fe}$ & $<1 \cdot 10^{-3}$ & $<1 \cdot 10^{-3}$ \\
$\mathrm{Ti}$ & $<5 \cdot 10^{-4}$ & $<5 \cdot 10^{-4}$ \\
$\mathrm{Al}$ & $<1 \cdot 10^{-3}$ & $<1 \cdot 10^{-2}$ \\
$\mathrm{Zr}$ & $<3 \cdot 10^{-3}$ & $<5 \cdot 10^{-3}$ \\
$\mathrm{Ca}$ & $<1 \cdot 10^{-3}$ & - \\
$\mathrm{Te}, \mathrm{Sb}$ & $<1 \cdot 10^{-3}$ & - \\
$\mathrm{Bi}$ & $<4 \cdot 10^{-4}$ &
\end{tabular}

дования, насколько нам известно, не проводились. Для интерпретации результатов исследования фотолюминесценции нами привлечены данные ИК спектроскопии в области валентных колебаний ОН-групп и оптической спектроскопии. Особенности дефектной структуры кристаллов, исследованных в данной работе, а также некоторые их оптические характеристики приведены в работах $[7,12-14]$.

\section{Методика эксперимента}

Все кристаллы выращены методом Чохральского в воздушной атмосфере на установке „Кристалл 2“. Использовалась гранулированная шихта ниобата лития, синтезированная в ИХТРЭМС КНЦ РАН. Подробно приготовление шихты, выращивание монокристаллов и подготовка образцов для исследований описаны в работах $[4,10,11,15,16]$. Примесный состав шихты и монокристаллов представлен в табл. 1 .

Регистрация спектров фотолюминесценции производилась спектрографом SL100M (Solar TII) с ПЗС-детектором (FLICCDML0673710) в интервале длин волн от 380 до $750 \mathrm{~nm}$ с шагом $\sim 0.2 \mathrm{~nm}$ при комнатной температуре. В качестве источника возбуждения использовался

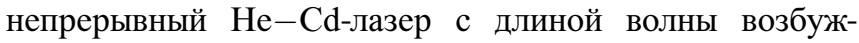
дения $325 \mathrm{~nm}$ и мощностью $15 \mathrm{~mW}$. Для уменьшения случайных флуктуаций сигнала ПЗС-матрица охлаждалась элементом Пельтье до $-30^{\circ} \mathrm{C}$. Время экспозиции равно $1 \mathrm{~s}$. Ширина входной щели монохроматора составляла $1.00 \mathrm{~mm}$. Из каждого спектра фотолюминесценции вычитался фоновый сигнал. Для регистрации спектров с объема кристалла использовалась 90-градусная геометрия рассеяния. При этом с целью устранения паразитного рассеянного излучения на щель спектрографа фокусировался только лазерный трек в кристалле. Остальное излучение отсекалось черным экраном с отверстием в виде сильно вытянутого прямоугольника по размеру лазерного трека. Кроме того, регистрация спектров фотолюминесценции осуществлялось в разных точках (не менее 5 раз) исследуемого образца с целью усреднения интенсивности люминесцентного сигнала. Для определения частоты и интенсивности максимумов люминесценции спектры были обработаны с использованием программ разделения контуров спектральных линий. Степень несовпадения модельного спектра фотолюминесценции с экспериментальным для всех образцов не превышала $1.35 \%$.

Регистрация ИК спектров производилась с помощью спектрометра IFS $66 \mathrm{v} / \mathrm{s}$ фирмы Bruker, спектров оптического поглощения - c помощью спектрофотометра СФ-256 УВИ. Край фундаментального оптического поглощения $\left(\lambda_{20}\right)$ был рассчитан для пластин исследованных кристаллов толщиной $1 \mathrm{~mm}$.

\section{Результаты и их обсуждение}

Спектры фотолюминесценции кристаллов $\mathrm{LiNbO}_{3 \text { stoich }}$, $\mathrm{LiNbO}_{3 \text { stoich }}\left(6.0 \mathrm{wt} \% \mathrm{~K}_{2} \mathrm{O}\right)$ и $\mathrm{LiNbO}_{3 \text { cong, }}$, полученные с объема образца, приведены на рис. 1. Видно, что в спектре каждого кристалла в области от 380 до $650 \mathrm{~nm}$ наблюдается гало, а также общий подъем интенсивности люминесценции в длинноволновой области $(>700 \mathrm{~nm})$, наиболее значительный для кристалла $\mathrm{LiNbO}_{3 \text { stoich }}\left(6.0 \mathrm{wt} \% \mathrm{~K}_{2} \mathrm{O}\right)$. В табл. 2 приведены основные характеристики полос люминесценции после разложения их на составляющие. Из рис. 1 и табл. 2 видно, что гало является сложным и содержит широкую полосу с главным максимумом при $527 \mathrm{~nm}\left(\mathrm{LiNbO}_{3 \text { stoich }}\right)$, $613 \mathrm{~nm}\left(\mathrm{LiNbO}_{3 \text { cong }}\right)$ и $612 \mathrm{~nm} \mathrm{LiNbO} 3$ stoich $\left(6.0 \mathrm{wt} \% \mathrm{~K}_{2} \mathrm{O}\right)$ и несколькими побочными максимумами при 402-423, $510-511,650-667$ и $698-701 \mathrm{~nm}$. Интегральная интенсивность спектра фотолюминесценции кристаллов $\mathrm{LiNbO}_{3 \text { stoich }}$ и $\mathrm{LiNbO}_{3 \text { stoich }}\left(6.0 \mathrm{wt} \% \mathrm{~K}_{2} \mathrm{O}\right)$ соответственно на $71 \%$ и $42 \%$ меньше интегральной интенсивности спектра кристалла $\mathrm{LiNbO}_{3 \text { cong, }}$ что свидетельствует о наиболее высокой излучательной способности кристалла $\mathrm{LiNbO}_{3 \text { cong }}$ в ряду исследованных кристаллов. Этому можно дать следующее объяснение.

Таблица 2. Количественные характеристики спектров фотолюминесценции монокристаллов $\mathrm{LiNbO}_{3}$

\begin{tabular}{c|c|c|c|c|c|c}
\hline \multicolumn{2}{c|}{ Полоса излучения } & 1 & 2 & 3 & 4 & 5 \\
\hline \multirow{3}{*}{$\mathrm{LiNbO}_{\text {3stoich }}$} & $I$, rel. units & 97 & 2519 & 187 & 959 & 1073 \\
& $w, \mathrm{~nm}$ & 47.2 & 230.4 & 36.1 & 44.6 & 47.2 \\
& $\lambda, \mathrm{nm}$ & 402 & 527 & 611 & 650 & 698 \\
\hline \multirow{3}{*}{$\mathrm{LiNbO}_{3 \text { cong }}$} & $I$, rel. units & 1176 & 5028 & 6976 & 451 & 1229 \\
& $w, \mathrm{~nm}$ & 75.9 & 157.5 & 199.1 & 38.5 & 33.3 \\
& $\lambda, \mathrm{nm}$ & 423 & 511 & 613 & 654 & 701 \\
\hline \multirow{2}{*}{$\mathrm{LiNbO}_{3 \text { stoich }}$} & $I$, rel. units & 1319 & 3746 & 3755 & 3014 & 1758 \\
$\left(6.0 \mathrm{wt}_{0} \mathrm{~K}_{2} \mathrm{O}\right)$ & $w, \mathrm{~nm}$ & 95.5 & 128.0 & 117.4 & 63.1 & 35.2 \\
& $\lambda, \mathrm{nm}$ & 407 & 510 & 612 & 667 & 700
\end{tabular}




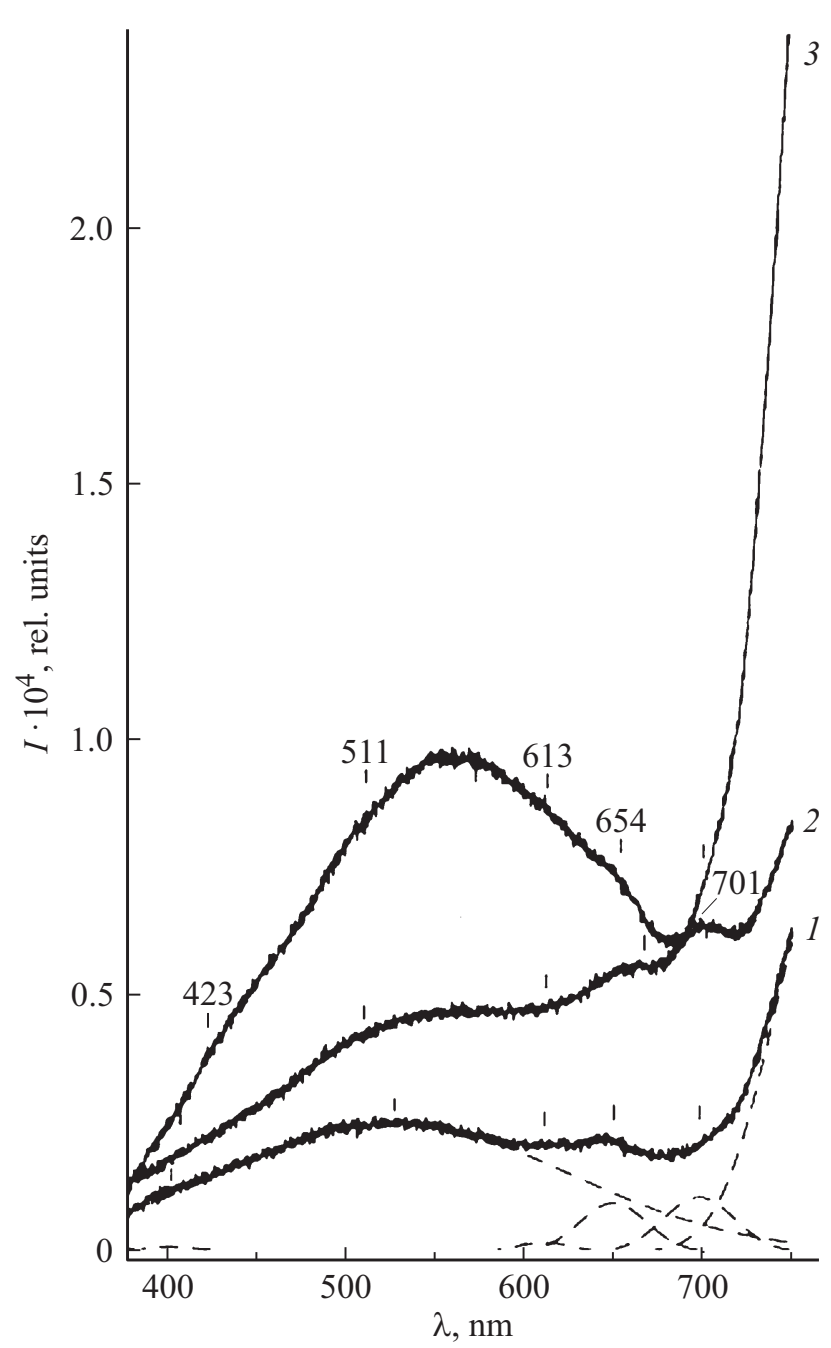

Рис. 1. Спектры фотолюминесценции монокристаллов $\mathrm{LiNbO}_{3 \text { stoich }}(1), \mathrm{LiNbO}_{3 \text { cong }}(2)$ и $\mathrm{LiNbO}_{3 \text { stoich }}\left(6.0 \mathrm{wt} \% \mathrm{~K}_{2} \mathrm{O}\right)(3)$. Ширина щели монохроматора $1 \mathrm{~mm}$.

В идеальном строго стехиометрическом $(R=\mathrm{Li} / \mathrm{Nb}=$ $=1)$ кристалле $\mathrm{LiNbO}_{3}$, в котором отсутствуют точечные дефекты $\mathrm{Nb}_{\mathrm{Li}}$, характеризующемся идеальным порядком расположения катионов вдоль полярной оси $(\mathrm{Li}, \mathrm{Nb}$, вакантный октаэдр $[2,10])$, может быть только один центр люминесценции, обусловленный наличием катионов $\mathrm{Nb}$, находящихся в своих позициях и являющихся глубокими электронными ловушками. В реальных высокосовершенных стехиометрических кристаллах $\mathrm{LiNbO}_{3}$, даже при условии $R=1$, всегда присутствуют немногочисленные собственные точечные дефекты $\mathrm{Nb}_{\mathrm{Li}}$, $V_{\mathrm{Li}}$ (катионы $\mathrm{Nb}$, вакансии, расположенные в позициях катионов Li) и др. [7,8]. Кроме того, присутствуют следовые количества многочисленных трудно контролируемых примесей металлов, являющихся глубокими и мелкими ловушками электронов. Для исследованных нами кристаллов концентрация каждой следовой примеси составляет $10^{-4}-10^{-3} \mathrm{wt} \%$, табл. 1. Таким образом, в реальных кристаллах даже с $R \sim 1$ может быть множе- ство центров люминесценции различной интенсивности. При этом обязательным условием является сохранение зарядового состояния катионной подрешетки в целом. Количество собственных катионов $\mathrm{Nb}$ и $\mathrm{Li}$ и вакантных октаэдров $V$ в кристалле $\mathrm{LiNbO}_{3}$, а также примесных катионов, расположенных не в своих позициях (центров свечения - дефектов $\mathrm{Nb}_{\mathrm{Li}}, V_{\mathrm{Li}}, V_{\mathrm{Nb}}$ и др.), возрастает с уменьшением величины $R$. При этом возрастает разупорядочение структурных единиц катионной подрешетки в целом $[2,12]$. Соответственно должна возрастать интенсивность полос люминесценции, отвечающих этим дефектным центрам.

Центрам свечения в виде дефектов $\mathrm{Nb}_{\mathrm{Li}}$ в легированных кристаллах $\mathrm{LiNbO}_{3}$ и номинально чистых кристаллах $\mathrm{LiNbO}_{3 \text { stoich }}, \mathrm{LiNbO}_{3 \text { stoich }}\left(6.0 \mathrm{wt} \% \mathrm{~K}_{2} \mathrm{O}\right)$ и $\mathrm{LiNbO}_{3 \mathrm{cong}}$ соответствуют максимумы полос люминесценции при $510-520 \mathrm{~nm}[17,18]$. Из табл. 2 видно, что интенсивность полос люминесценции с максимумами при $510-527 \mathrm{~nm}$ увеличивается в ряду кристаллов $\mathrm{LiNbO}_{3 \text { stoich }}, \mathrm{LiNbO}_{3 \text { stoich }}\left(6.0 \mathrm{wt} \% \mathrm{~K}_{2} \mathrm{O}\right), \mathrm{LiNbO}_{3 \text { cong }}$, что свидетельствует о последовательном увеличении количества точечных дефектов $\mathrm{Nb}_{\mathrm{Li}}$ в этом ряду кристаллов. При этом вследствие сохранения зарядовой нейтральности катионной подрешетки в целом возрастает количество вакантных кислородных октаэдров $[2,3,19]$ и происходят изменения в строении комплексных дефектов, обусловленных наличием гидроксильных групп ОН в структуре кристалла $[12,13]$. В кристалле $\mathrm{LiNbO}_{3 \text { cong }}(R=0.946)$ количество дефектов $\mathrm{Nb}_{\mathrm{Li}}$ составляет $\sim 6 \mathrm{wt} \%[2,3]$, что намного больше, чем в кристаллах $\mathrm{LiNbO}_{3 \text { stoich }}$ и $\mathrm{LiNbO}_{3 \text { stoich }}\left(6.0 \mathrm{wt} \% \mathrm{~K}_{2} \mathrm{O}\right)$ [1]. Локализация атомов водорода в каждом из этих кристаллов также имеет свои особенности [12].

Концентрацию точечных дефектов $\mathrm{Nb}_{\mathrm{Li}}$ и $V_{\mathrm{Li}}$ в кристаллической решетке беспримесных кристаллов $\mathrm{LiNbO}_{3}$, согласно модели компенсации Li-вакансий $[2,19]$, можно рассчитать по формулам [20]

$$
\begin{gathered}
C\left(V_{\mathrm{Li}}\right)=\left(\frac{4-4 \times \mathrm{Li} / \mathrm{Nb}}{5+\mathrm{Li} / \mathrm{Nb}}\right) \times 100, \\
C\left(\mathrm{Nb}_{\mathrm{Li}}\right)=\frac{\mathrm{C}\left(V_{\mathrm{Li}}\right)}{4} .
\end{gathered}
$$

Величину $R \mathrm{Li} / \mathrm{Nb}$ в кристаллах ниобата лития разного состава можно оценить двумя независимыми методами: по интенсивности полос в спектре ИК поглощения, соответствующих валентным колебаниям ОН-групп, согласно методике, предложенной в [20] и используя данные о крае фундаментального оптического поглощения по формуле:

$$
\mathrm{Li} / \mathrm{Nb}=1-\left(\frac{\lambda_{20}-301.5}{81.29}\right)^{2}
$$

где $\lambda_{20}-$ край фундаментального оптического поглощения, табл. 3. Результаты расчетов величины $R$ $\mathrm{Li} / \mathrm{Nb}$ и концентрации точечных дефектов $\mathrm{Nb}_{\mathrm{Li}}^{4+}$ и $V_{\mathrm{Li}}^{-}$ в исследованных кристаллах приведены в табл. 3. 
Таблица 3. Край фундаментального оптического поглощения $\left(\lambda_{20}\right)$, отношение $\mathrm{Li} / \mathrm{Nb}$ (определенное по краю фундаментального поглощения - $\mathrm{Li} / \mathrm{Nb}^{*}$ и по ИК спектру поглощения $\left.-\mathrm{Li} / \mathrm{Nb}^{* *}\right)$, концентрация $\mathrm{OH}-г$ рупп $\left(\mathrm{C}_{\mathrm{OH}}^{-}\right)$и точечных дефектов $\mathrm{Nb}_{\mathrm{Li}}^{4+}$ и $V_{\mathrm{Li}}^{-}$ в кристаллах ниобата лития при $t=25^{\circ} \mathrm{C}$

\begin{tabular}{c|c|c|c|c|c|c}
\hline Кристалл & $\lambda_{20}, \mathrm{~nm}$ & $\mathrm{Li} / \mathrm{Nb}^{*}$ & $\mathrm{Li} / \mathrm{Nb}^{* *}$ & $C\left(\mathrm{Nb}_{\mathrm{Li}}\right), \mathrm{mol} \%$ & $C\left(V_{\mathrm{Li}}^{-}\right), \mathrm{mol}^{\%}$ & $C_{\mathrm{OH}}^{-}, \mathrm{cm}^{-3}$ \\
\hline $\mathrm{LiNbO}_{3 \text { cong }}$ & 319.9 & 0.949 & 0.942 & 0.98 & 3.90 & $3.26 \cdot 10^{17}$ \\
$\mathrm{LiNbO}_{3 \text { stoich }}$ & 311.0 & 0.986 & 0.988 & 0.20 & 0.80 & $1.58 \cdot 10^{17}$ \\
$\mathrm{LiNbO}_{3 \text { stoich }}\left(6.0 \mathrm{wt} \% \mathrm{~K}_{2} \mathrm{O}\right)$ & 310.0 & 0.989 & 0.991 & 0.15 & 0.60 & $2.49 \cdot 10^{17}$
\end{tabular}

Из табл. 3 видно, что количество дефектов $\mathrm{Nb}_{\mathrm{Li}}$ минимально в кристалле $\mathrm{LiNbO}_{3 \text { stoich }}\left(6.0 \mathrm{wt} \% \mathrm{~K}_{2} \mathrm{O}\right)$. В то же время интенсивность полосы фотолюминесценции при $510 \mathrm{~nm}$, соответствующей дефектам $\mathrm{Nb}_{\mathrm{Li}}$, не минимальна в спектре кристалла $\mathrm{LiNbO}_{3 \text { stoich }}\left(6.0 \mathrm{wt} \% \mathrm{~K}_{2} \mathrm{O}\right)$. Причина этого несоответствия может заключаться в следующем. Из рис. 1 видно, что в спектрах фотолюминесценции исследованных кристаллов присутствует полоса с максимумом при $611-613 \mathrm{~nm}$. Причем интенсивность максимума при $612 \mathrm{~nm}$ в кристалле $\mathrm{LiNbO}_{3 \text { stoich }}(6.0 \mathrm{wt} \%$ $\left.\mathrm{K}_{2} \mathrm{O}\right)$ в 20 раз больше интенсивности соответствующего максимума при $611 \mathrm{~nm}$ в кристалле $\mathrm{LiNbO}_{3 \text { stoich, }}$ табл. 2. Столь большие различия в интенсивности максимума при 611-613 nm для исследованных кристаллов можно объяснить с точки зрения наличия люминесценции комплексного дефекта в виде биполярона $\mathrm{Nb}_{\mathrm{Nb}}^{4+}-\mathrm{Nb}_{\mathrm{Li}}^{4+}$. Одно из теоретически рассчитанных значений оптических переходов у биполярона $\left(\mathrm{Nb}_{\mathrm{Li}}^{4+}-\mathrm{Nb}_{\mathrm{Nb}}^{4+}\right)$ равно $2.0 \mathrm{eV}$ $(620 \mathrm{~nm})$ [21,22]. Этот факт позволяет предположить, что если интенсивность излучения отдельного центра свечения в первом приближении зависит только от концентрации отдельного вида дефектов, то количество центров свечения данного и других дефектов увеличивается по мере уменьшения величины $R$ : оно максимально для кристалла $\mathrm{LiNbO}_{3 \text { cong }}$ и минимально для $\mathrm{LiNbO}_{3 \text { stoich, }}$, табл. 2. Однако этот результат также не согласуется с рассчитанным отношением $\mathrm{Li} / \mathrm{Nb}$ в исследованных кристаллах, табл. 3. Отношение $\mathrm{Li} / \mathrm{Nb}$ в кристалле $\mathrm{LiNbO}_{3 \text { stoich }}\left(6.0 \mathrm{wt} \% \mathrm{~K}_{2} \mathrm{O}\right)$ даже незначительно выше,

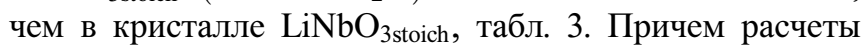
отношения $\mathrm{Li} / \mathrm{Nb}$ для исследованных кристаллов были проведены по данным о крае фундаментального поглощения и по данным ИК спектров поглощения в области валентных колебаний ОН-групп, результаты которых согласуются между собой, табл. 3. Следовательно, можно предположить, что в исследованных кристаллах наблюдается перенос поглощенной энергии между центрами свечения, что обуславливает различия с экспериментальными данными, полученными при исследовании ИК спектров и края фундаментального поглощения.

Из рис. 1 и табл. 2 видно, что максимум при $527 \mathrm{~nm}$ полосы люминесценции, обусловленный точечными дефектами $\mathrm{Nb}_{\mathrm{Li}}$, для кристалла $\mathrm{LiNbO}_{3 \text { stoich }}$ смещен по сравнению с аналогичными максимумами для кристаллов $\mathrm{LiNbO}_{3 \text { cong }}(511 \mathrm{~nm})$ и $\mathrm{LiNbO}_{3 \text { stoich }}(6.0 \mathrm{wt} \%$ $\left.\mathrm{K}_{2} \mathrm{O}\right)(510 \mathrm{~nm})$ в длинноволновую сторону, что может

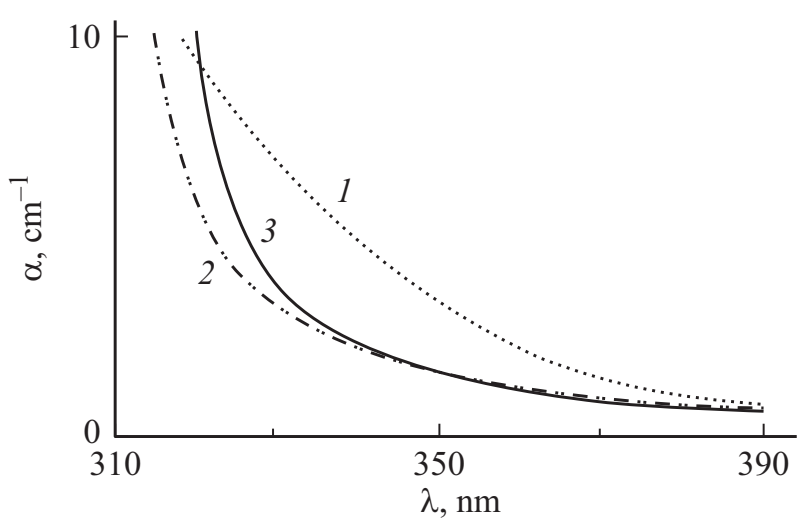

Рис. 2. Спектры оптического поглощения кристаллов: 1 $\mathrm{LiNbO}_{3 \text { stoich, }} 2-\mathrm{LiNbO}_{3 \text { stoich }}\left(6.0 \mathrm{wt} \% \mathrm{~K}_{2} \mathrm{O}\right), 3-\mathrm{LiNbO}_{3 \text { cong. }}$.

быть связано с высокой неоднородностью показателя преломления кристалла $\mathrm{LiNbO}_{3 \text { stoich }}$ вдоль оси роста. Это подтверждается различным поведением оптического поглощения кристаллов в области края фундаментального поглощения, рис. 2. Спектры оптического поглощения для исследования оптической неоднородности кристаллов были получены для образцов размерами $\sim 8 \times 7 \times 6 \mathrm{~mm}$. Видно, что край фундаментального оптического поглощения кристаллов $\mathrm{LiNbO}_{3 \text { stoich }}(6.0 \mathrm{wt} \%$ $\left.\mathrm{K}_{2} \mathrm{O}\right)$ и $\mathrm{LiNbO}_{3 \text { cong }}$ смещен в коротковолновую область и является более крутым по сравнению с краем опти-

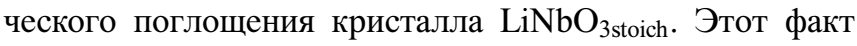
указывает на более высокую однородность показателя преломления в кристаллах $\mathrm{LiNbO}_{3 \text { stoich }}\left(6.0 \mathrm{wt} \% \mathrm{~K}_{2} \mathrm{O}\right.$ и $\mathrm{LiNbO}_{3 \text { cong }}$ по сравнению с кристаллом $\mathrm{LiNbO}_{3 \text { stoich }}$ Худшая оптическая однородность кристалла $\mathrm{LiNbO}_{3 \text { stoich }}$ по сравнению с кристаллами $\mathrm{LiNbO}_{3 \text { stoich }}\left(6.0 \mathrm{wt} \% \mathrm{~K}_{2} \mathrm{O}\right)$ и $\mathrm{LiNbO}_{3 \text { cong }}$ подтверждается также данными лазерной коноскопии $[12,14]$.

При освещении кристалла ниобата лития лазерным излучением имеют место два конкурирующих процесca. С одной стороны, при увеличении упорядочения структурных единиц катионной подрешетки при $R \rightarrow 1$ в кристалле $\mathrm{LiNbO}_{3}$ уменьшается количество заряженных точечных дефектов и связанных с ними глубоких уровней захвата в запрещенной зоне. Одновременно увеличивается количество мелких ловушек („уровней прилипания“ в запрещенной зоне [23]) и соответственно увеличивается вероятность излучательной рекомби- 
нации фотовозбужденных носителей. Основная часть фотоэлектронов захватывается имеющимися глубокими ловушками. Следовательно, больше становятся нескомпенсированные внутренние электрические поля, влияющие на показатель преломления и определяющие фоторефрактивные свойства кристалла. Этим, по-видимому, и объясняется больший эффект фоторефракции в более структурно совершенных кристаллах $\mathrm{LiNbO}_{3 \text { stoich }}$ по сравнению с кристаллом $\mathrm{LiNbO}_{3 \text { cong. }}$ Однако в данном объяснении не учитываются изменения, происходящие в комплексных дефектах, чувствительных к изменению кристаллического поля, к изменению величины $R$.

На оптические и электрические свойства кристаллов ниобата лития сильно влияет присутствие в структуре гидроксильных групп ОН, которые занимают места ионов кислорода $[1,12,24]$. Образование водородной связи приводит не только к кардинальному изменению волновых функций внешних электронных орбиталей иона кислорода и параметров его электронной поляризуемости, но и к сильному искажению всего октаэдра $\mathrm{MeO}_{6}$ $(\mathrm{Me}-$ основные $(\mathrm{Li}, \mathrm{Nb})$ или примесные катионы), не исключая образования полярона $\mathrm{Nb}^{4+}$ [25]. При этом атомы водорода могут локализоваться в структуре номинально чистого кристалла в трех различных позициях в составе комплексных дефектов $\mathrm{Me}-\mathrm{OH}$ и $\mathrm{Me}-\mathrm{OH}-\mathrm{Me}\left(V_{\mathrm{Li}}\right)(\mathrm{Me}-$ примесный или основной катион) [24]. Наличие таких комплексных дефектов, содержащих в себе несколько центров свечения, может приводить к люминесценции в видимой и ближней ИК области спектра, а также к передаче энергии между центрами свечения, к изменению положения энергетических уровней, локализованных в запрещенной зоне.

В работах $[1,26]$ для высокосовершенного стехиометрического кристалла $\mathrm{LiNbO}_{3}$, выращенного методом HTTSSG, в котором существует только одна позиция атома водорода, авторы наблюдали только одну интенсивную широкую полосу люминесценции с максимумом при $443 \mathrm{~nm}$. По мнению авторов [26], механизм излучения данной полосы связан с электроннодырочной рекомбинацией между $\mathrm{Nb}^{4+}-\mathrm{O}^{-}$. При этом катион $\mathrm{Nb}^{5+}$ находится в своем октаэдре. В тоже время для стехиометрического кристалла $\mathrm{LiNbO}_{3 \text { stoich }}$ $\left(6.0 \mathrm{wt} \% \mathrm{~K}_{2} \mathrm{O}\right)$, также полученного методом HTTSSG, как и для кристалла $\mathrm{LiNbO}_{3 \text { stoich, }}$ мы наблюдали 5 полос люминесценции с максимумами при 402-407, 510-527, $611-612,650-667$ и $698-700 \mathrm{~nm}$, рис. 1 , табл. 2. Отличие данных работы [26] и наших данных может быть обусловлено тем, что в исследованных нами кристаллах $\mathrm{LiNbO}_{3 \text { stoich }}\left(6.0 \mathrm{wt} \% \mathrm{~K}_{2} \mathrm{O}\right)$ и $\mathrm{LiNbO}_{3 \text { stoich }}$, как и в кристалле $\mathrm{LiNbO}_{3 \text { cong }}$, атомы водорода занимают большее количество позиций, что приводит к большему числу активных центров свечения.

На рис. 3 приведены спектры ИК поглощения в области валентных колебаний водородных связей монокристаллов $\mathrm{LiNbO}_{3 \text { stoich }}, \mathrm{LiNbO}_{3 \text { cong }}$ и $\mathrm{LiNbO}_{3 \text { stoich }}(6.0 \mathrm{wt} \%$ $\mathrm{K}_{2} \mathrm{O}$ ). В спектрах всех исследованных кристаллов в

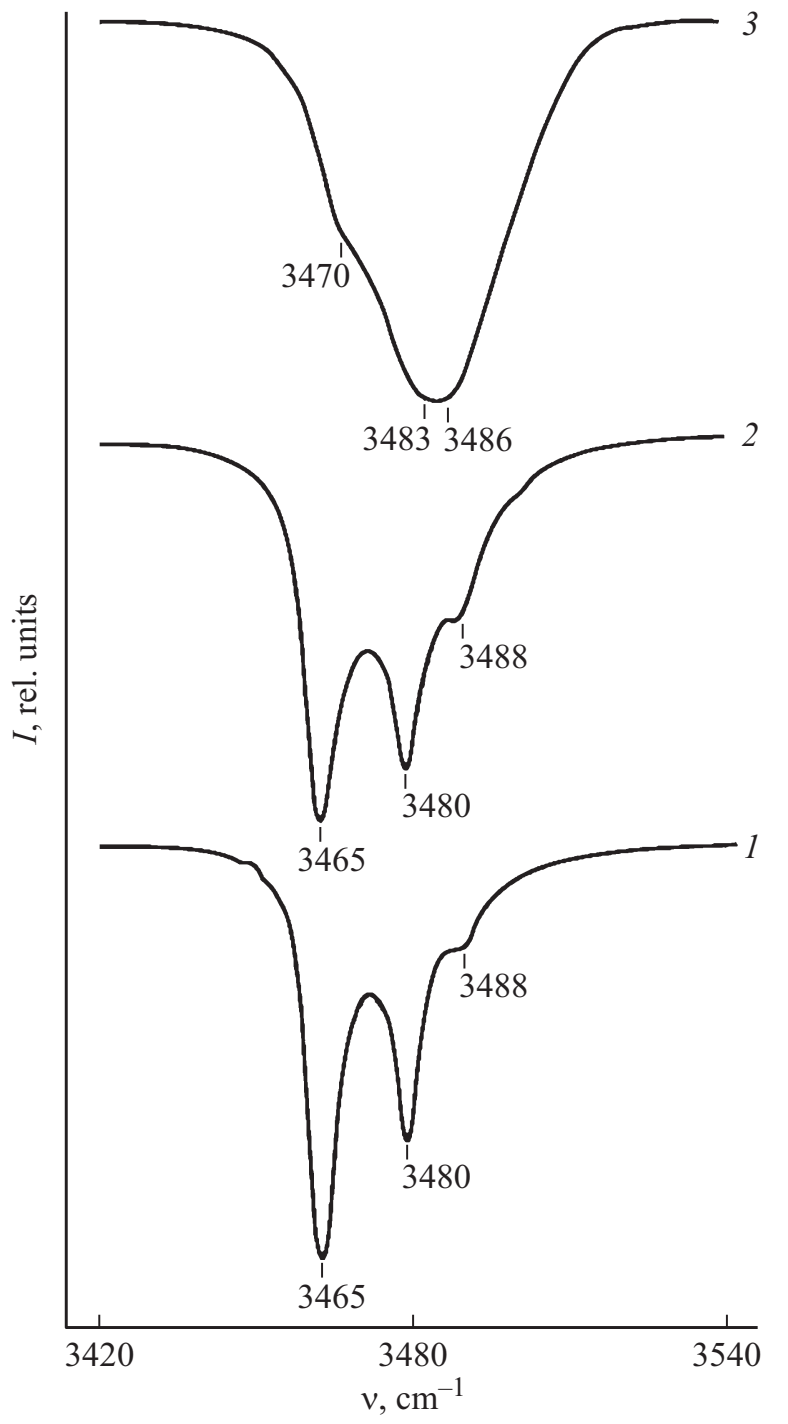

Рис. 3. ИК спектры поглощения в области валентных колебаний ОН-групп номинально чистых монокристаллов ниобата лития разного состава: $1-\mathrm{LiNbO}_{3 \text { stoich }}, 2-\mathrm{LiNbO}_{3 \text { stoich }}$ $\left(6.0 \mathrm{wt} \% \mathrm{~K}_{2} \mathrm{O}\right), 3-\mathrm{LiNbO}_{3 \text { cong }}$.

области $3420-3540 \mathrm{~cm}^{-1}$ проявляются три интенсивные полосы поглощения с частотами 3465-3470 $\left(v_{1}\right)$, $3480-3483\left(v_{2}\right), 3486-3488\left(v_{3}\right) \mathrm{cm}^{-1}$, что свидетельствует о наличии трех позиций атомов водорода в структуре кристалла. Различия в частотах полос поглощения для всех кристаллов незначительные, что свидетельствует о практически одинаковых значениях квазиупругих постоянных связей $\mathrm{O}-\mathrm{H}$. Однако интенсивности и ширины полос поглощения для кристалла $\mathrm{LiNbO}_{3 \text { cong }}$ значительно отличаются от таковых для кристаллов $\mathrm{LiNbO}_{3 \text { stoich }}$ и $\mathrm{LiNbO}_{3 \text { stoich }}\left(6.0 \mathrm{wt} \% \mathrm{~K}_{2} \mathrm{O}\right)$, рис. 3, что указывает на разную концентрацию ОНгрупп в разных позициях в структуре исследованных кристаллов, а также на разную степень упорядочения ОН-связей. Более узкие полосы поглощения в ИК спектре кристаллов $\mathrm{LiNbO}_{3 \text { stoich }}$ и $\mathrm{LiNbO}_{3 \text { stoich }}\left(6.0 \mathrm{wt} \% \mathrm{~K}_{2} \mathrm{O}\right)$, 
рис. 3, указывают на больший порядок в расположении соответствующих ОН-групп в структуре кристаллов по

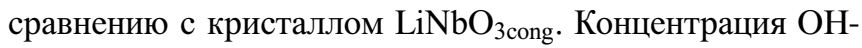
групп в исследованных кристаллах была рассчитана из спектра ИК поглощения по методу Клавира [27]. Результаты расчета представлены в табл. 3. Полученные результаты показывают, что в кристалле $\mathrm{LiNbO}_{3 \text { cong }}$ концентрация ОН-групп максимальная, а количество ОНгрупп в кристалле $\mathrm{LiNbO}_{3 \text { stoich }}\left(6.0 \mathrm{wt} \% \mathrm{~K}_{2} \mathrm{O}\right)$ является промежуточным между кристаллами $\mathrm{LiNbO}_{3 \text { cong }}$ и $\mathrm{LiNbO}_{3 \text { stoich, табл. } 3 .}$

Природа малоинтенсивных центров свечения в областях при $\lambda \sim 380-400$ и $>650 \mathrm{~nm}$, рис. 1, табл. 2, остается пока не ясной. Возможно, в объеме кристалла могут активироваться центры свечения, связанные с вакансиями по литию и ниобию, либо происходить нарушение анионной подрешетки с образованием кислородных вакансий. Максимум вблизи $\sim 650 \mathrm{~nm}$, табл. 2, может быть обусловлен генерацией второй гармоники лазерного излучения в фотолюминесцентных спектрах исследуемых образцов.

\section{Заключение}

Исследования спектров фотолюминесценции кристаллов $\mathrm{LiNbO}_{3 \text { cong }}, \mathrm{LiNbO}_{3 \text { stoich }}\left(6.0 \mathrm{wt} \% \mathrm{~K}_{2} \mathrm{O}\right)$ и $\mathrm{LiNbO}_{3 \text { stoich, }}$, полученных при возбуждении линией $325 \mathrm{~nm} \mathrm{c} \mathrm{объ-}$ ема кристалла, показывают, что фотолюминесценция неоднозначно зависит от стехиометрии и технологии получения кристалла. В кристалле $\mathrm{LiNbO}_{3 \text { cong }}$ доминирующими центрами свечения с максимумами при 511 и $613 \mathrm{~nm}$ являются центры в виде дефектов $\mathrm{Nb}_{\mathrm{Li}}$, являющихся наиболее глубокими электронными ловушками. В кристаллах $\mathrm{LiNbO}_{3 \text { stoich }}\left(6.0 \mathrm{wt} \% \mathrm{~K}_{2} \mathrm{O}\right)$ и $\mathrm{LiNbO}_{3 \text { stoich }}$ практически отсутствуют точечные дефекты $\mathrm{Nb}_{\mathrm{Li}}$, но люминесценция соответствующих центров свечения с максимумами при 510-527 nm достаточно интенсивная, особенно для кристалла $\mathrm{LiNbO}_{3 \text { stoich }}\left(6.0 \mathrm{wt} \% \mathrm{~K}_{2} \mathrm{O}\right)$. Согласно проведенным расчетам, в структуре кристалла $\mathrm{LiNbO}_{3 \text { stoich }}\left(6.0 \mathrm{wt} \% \mathrm{~K}_{2} \mathrm{O}\right)$ наблюдается повышенное содержание ОН-групп по сравнению с кристаллом

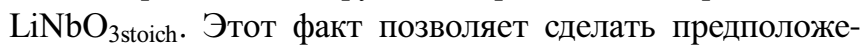
ние, что вклад в люминесценцию могут вносить не только основные типы центров свечения в виде точечных дефектов (когда основные и примесные катионы расположены не в своих позициях), но центры свечения в виде комплексных дефектов с участием атомов водорода. В длинноволновой области спектра, вследствие рассеяния энергии на колебаниях кристаллической решетки, имеет место более сильное тушение всех центров люминесценции в кристалле $\mathrm{LiNbO}_{3 \text { cong }}$ по сравнению с кристаллами $\mathrm{LiNbO}_{3 \text { stoich }}$ и $\mathrm{LiNbO}_{3 \text { stoich }}\left(6.0 \mathrm{wt} \% \mathrm{~K}_{2} \mathrm{O}\right)$.

\section{Благодарность}

Авторы выражают благодарность В.Б. Пикулеву за помощь в постановке физического эксперимента и обсуждение экспериментальных данных.

\section{Конфликт интересов}

Авторы заявляют, что у них нет конфликта интересов.

\section{Список литературы}

[1] Lengyel K., Peter A., Kovacs L., Corradi G., Palfalvi L., Hebling J., Unferdorben M., Dravecz G., Hajdara I., Szaller Zs., Polgar K. // Appl. Phys. Rev. 2015. V. 2. P. 040601-1. doi 10.1063/1.4929917

[2] Сидоров Н.В., Волк Т.Р., Маврин Б.Н., Калинников В.Т. Ниобат лития: дефекты, фоторефракция, колебательный спектр, поляритоны. М.: Наука, 2003. 255 с.

[3] Кузьминов Ю.С. Электрооптический и нелинейнооптический кристалл ниобата лития. М.: Наука, 1987. 262 с.

[4] Палатников М.Н., Сидоров Н.В., Макарова О.В., Бирюкова И.В. Фундаментальные аспекты технологии сильно легированных кристаллов ниобата лития. Апатиты: Издво КНЦ РАН, 2017. 241 с

[5] Палатников М.Н., Макарова О.В., Сидоров Н.В. Ростовые и технологические дефекты кристаллов ниобата лития различного генезиса. Апатиты: Изд-во КНЦ РАН, 2018. $89 \mathrm{c}$.

[6] Palatnikov M.N., Sidorov N.V. Oxide Electronics and Functional Properties of Transition Metal Oxides. USA: NOVA Sience Publichers, 2014. P. 31-168.

[7] Сидоров Н.В., Палатников М.Н., Теплякова Н.А., Сюй А.В., Киле E.О., Штарев Д.С. // Неорг. матер. 2018. T. 54. № 6. C. 611. doi 10.7868/S0002337X18060106; Sidorov N.V., Palatnikov M.N., Teplyakova N.A., Syuy A.V., Kile E.O., Shtarev D.S. // Inorg. Mater. 2018. V. 54. N 6. P. 581. doi 10.1134/S0020168518060134

[8] Shur V.Ya., Akhmatkhanov A.R., Baturin I.S. // Appl. Phys. Rew. 2015. V. 2. N 4. P. 040604. doi 10.1063/1.4928591

[9] Polgar K., Peter A., Kovacs L., Corradi G., Szaller Zs. // J. Cryst. Growth. 1997. V. 177. N 3-4. P. 211. doi 10.1016/S0022-0248(96)01098-6

[10] Бирюкова И.В., Габриелян В.Т., Калинников В.Т., Палатников М.Н. // Тезисы докладов IX Национальной конференции по росту кристаллов. М., 2000. С. 443.

[11] Баласанян Р.Н., Вартанян Э.С., Габриелян В.Т., Казарян Л.М. Авт. свидетельство № 845506, 06.03.1981.

[12] Сидоров Н.В., Палатников М.Н., Бобрева Л.А. // Журн. структ. хим. 2019. Т. 60. № 9. С. 1434. doi 10.26902/JSC_id46180; Sidorov N.V., Palatnikov M.N., Bobreva L.A. // J. Struct. Chem. 2019. V. 60. P. 1434. doi 10.26902/JSC_id46180

[13] Сидоров Н.В., Палатников М.Н., Бобрева Л.А., Климин С.A. // Неорг. матер. 2019. Т. 55. № 4. С. 395. doi 10.1134/S0002337X19040134; Sidorov N.V., Palatnikov M.N., Bobreva L.A., Klimin C.A. // Inorg. Mater. 2019. V. 55. N 4. P. 365. doi 10.1134/S0020168519040137

[14] Теплякова Н.А., Сидоров Н.В., Палатников М.Н. // Персп. матер. 2016. № 4. С. 19.

[15] Palatnikov M.N., Biryukova I.V., Sidorov N.V., Denisov A.V., Kalinnikov V.T., Smith P.G.R., Shur V.Ya. // J. Cryst. Growth. 2006. V. 291. P. 390. doi 10.1016/j.jcrysgro.2006.03.022 
[16] Палатников М.Н., Сидоров Н.В., Бирюкова И.В., Щербина О.Б., Калинников В.Т. // Персп. Матер. 2011. № 2. C. 93.

[17] Emond M.H.J., Wiegel M., Blasse G., Feigelson R. // Mat. Res. Bull. 1993. V. 28. N 10. P. 1025. doi 10.1016/00255408(93)90140-9

[18] Krol D.M., Blasse G., Powell R.C. // J. Chem. Phys. 1980. V. 73. N 1. P. 163. doi 10.1063/1.439901

[19] Volk T., Wöhlecke M. Lithium Niobate. Defects, Photorefraction and Ferroelectric Switching. Berlin: Springer, 2008. 250 p.

[20] Саллум М.И., Грунский О.С., Маньшина А.А., Тверьянович А.С., Тверьянович Ю.С. // Изв. РАН. Сер. хим. 2009. T. 73. № 11. C. 2162; Salloum M.Y., Grunsky O.S., Manishina A.A., Tveriyanovich A.S., Tveriyanovich Yu.S. // Russ. Chem. Bull., Int. Ed. 2009. V. 58. P. 2228.

[21] Ахмадуллин И.Ш., Голенищев-Кутузов В.А., Мигачев C.A. // ФТТ. 1998. Т. 40. № 6. C. 1109; Akhmadullin I.Sh., Golenishchev-Kutuzov V.A., Migachev S.A. // Phys. Sol. St. 1998. V. 40. N 6. P. 1012. doi $10.1134 / 1.1130478$

[22] Schirmer O.F., Thiemann O., Wöhlecke M. // J. Phys. Chem. Sol. 1991. V. 52. N 1. P. 185. doi 10.1016/00223697(91)90064-7

[23] Блистанов А.А., Любченко В.М., Горюнова А.Н. // Кристаллогр. 1998. Т. 43. № 1. С. 86.

[24] Cabrera J.M., Olivares J., Carrascosa M., Rams J., Müller R. \& Diéguez E. // Adv. Phys. 1996. V. 45. N 5. P. 349. doi 10.1080/00018739600101517

[25] Евдокимов С.В., Яценко А.В. // Кристаллогр. 2003. Т. 48. № 4. C. 594; Yevdokimov S.V., Yatsenko A.V. // Cryst. Rep. 2003. V. 48. N 4. P. 542. doi 10.1134/1.1595175

[26] Fischer C., Wöhlecke M., Volk T., Rubinina N. // Phys. stat. sol. (A). 1993. V. 137. P. 247. doi 10.1002/pssa.2211370122

[27] Klauer S., Wöhlecke M., Kapphan S. // Phys. Rev. B. 1992. V. 45. P. 2786. doi 10.1103/PhysRevB.45.2786 